\title{
Particle Count and Size Analyzer
}

National Cancer Institute

\section{Source}

National Cancer Institute. Particle Count and Size Analyzer. NCI Thesaurus. Code C62330.

An instrument that measures changes in the electrical resistance of an electrolyte solution produced by suspended nonconductive particles. Changes in resistance determine both the concentration and size distribution of the particles. 